\title{
Exploring Instructional Leadership Practices in Institutional Schools of Kathmandu: A Narrative Inquiry
}

\section{Subash Shrestha*}

Department of Educational Leadership, Kathmandu University School of Education, Nepal

\section{Abstract}

Principals of schools are more focused on managerial work rather than supporting teaching and learning in the school. As a result, they spend most of their time behind the desk and in work pertaining to documentation. Principals are guided by the principles of achieving good grades in examinations. They tend to be more focused on rote learning rather than knowledge and skills-based learning that add value to the lives of students. However, the instructional leadership advocates that the principal should be able to create school cultures that encourage students' progress by ensuring teachers' accountability. Thus, the main aim of the paper is to explore perception and practices of principals on their instructional leadership in addressing the skills required for the $21^{\text {st }}$ century. This research makes use of applied narrative approach to explore the perceptions and practices. For this purpose, this study undertook in-depth interviews with two principals from different schools of the Kathmandu valley. The findings of the study revealed that setting

*Correspondence should be addressed to Mr. Subash Shrestha, Department of Educational Leadership, Kathmandu University School of Education, Nepal.

Email:subash@kusoed.edu.np

https://orcid.org/0000-0002-4229-1323

(Received 4th April 2021; Revised $11^{\text {th }}$ June 2021; Accepted 15th June 2021 (C) OUSL)

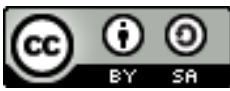

This article is published under the Creative Commons Attribution-Share Alike 4.0 International License (CC-BY-SA). This license permits use, distribution and reproduction in any medium; provided it is licensed under the same terms and the original work is properly cited. 
direction, focusing in curriculum and monitoring the learners' progress are the perception and practices of instructional leadership.

Keywords: Instructional leadership, Institutional schools, Leadership and management practices

\section{Introduction}

In 1984 this researcher's father, a non-academician, established a school based on requests from a group of close associates who were teachers. The school performed well and became popular in its area in terms of students' enrollment and their achievements. After five years, the teachers demanded their share in the institution which the founder of the school refused. As a consequence, the teachers resigned from their posts and established another school. During the initial stage, their departure did not affect the original school visibly though with time their absence was felt as the school's management standards and academic achievements began to decline. However, despite these concerns, the school continued to operate. To assist the school in whatever the way possible, this researcher would spend some time there daily after college class. The researcher was deeply inspired by his college's extra-curricular activities and tried to incorporate them in the school. In addition, this researcher worked as a part-time teacher of English in the school. With the advent of the new millennium, the leadership of the school was entrusted to this researcher, reminding Bush's (2006) statement that school principals in the developing countries were appointed based on a successful record as teachers with the assumption that this provided a sufficient starting point for school leadership. For a fresh undergraduate with only practical, yet unsystematic knowledge of teaching and learning, this was a daunting challenge.

Initially, the school was managed as per the norm that had established itself under its founder, which was a time-tested traditional mode of management with the focus on obtaining better Secondary Education Exam (SEE) results. Coming from a school that maintained its position in the top ten ranking in producing the best SEE results, the school was run by this researcher with strict focus on gaining top marks. In 
this respect, Huber (2004) argued that a school cannot any longer be regarded as simply imparting traditional knowledge within a fixed frame. Rather it is becoming an organization which needs to renew itself continuously in order to take present and future needs into account.

For three decades, this researcher managed the school on those lines and produced 23 SEE batches with top marks. This period had this researcher desk bound and dealing with reams of document focusing on financial matters. Over a period of time, this researcher witnessed the inadequacy of this method on his personal and professional growth. In the meantime, academic exposure to M.Ed. Leadership and Management Program of the Kathmandu University offered this researcher fresh perspectives on inadequate school leadership (Leithhood et al, 2006). Harris (2009) said that effective school leadership determines school improvement. According to Bush (2007), there has been a great interest in educational leadership during the early part of the $21^{\text {st }}$ century because of the widespread belief that the quality of leadership makes a significant difference to school and student outcomes. In many parts of the world, there is recognition that schools require effective leaders and managers if they are to provide the best possible education for their students (Bush, 2007). Much of the available literature on effective school leadership indicates that school leaders play an important role by exerting their influence over several factors, including, most importantly, teachers (Hallinger \& Heck, 1998; Leithwood et al., 2004). Effective school leadership directly affects teacher capacity, motivation, and commitment and working conditions, all of which directly affect teaching practices linked to student learning and achievement (Leithwood et al., 2008). According to Louis et al. (2010), school leaders influence student learning mainly through establishing appropriate school conditions by setting goals, influencing culture, setting parameters for classroom conditions through designing and managing curricular planning and resource allocations, and also by directly influencing teachers. The review of literature conducted by Hallinger \& Heck (1998) on instructional leadership literature published between 1980 and 1995 suggests that school principals who employ an instructional leadership had an indirect effect on 
students' reading achievement and direct effects on schools' climate changing in elementary schools. Additionally, Spiro (2013) affirms that instructional leaders establish clear goals, provide educators with direction and sense of mission. Furthermore, they motivate educators to enhance their performance. Teacher motivation is also highlighted as having a drive that leads to improved educational outcomes. This knowledge and awareness on leadership practices finally has given this researcher the background to issues like how school principals practice and perceive instructional leadership in their schools. Thus, this research attempts to throw light upon the instructional leadership practices in institutional schools of Kathmandu.

Instructional leadership is not a new concept. Salo, Nylund \& Stjernstrom (2014) said that the origin of instructional leadership was an Anglo-American concept developed intensely in the early 1980s for effective school management. However, critics argued that instructional leadership as an outdated and authoritative position of the principal (Sebastian \& Allenswoth, 2012). In the same lines, Hallinger (2003) had a view that principals could not have the capabilities of being curriculum experts in all the learning areas so they might be ineffective in managing the school. However, instructional leadership has been reawakened as a form of leadership for learning that aimed to achieve goals set by the school. Adjectives such as collective, shared, transformational and distributed are used with instructional leadership (Louis \& Wahlstrom, 2012). This issue needs to be explored in institutional schools where the principals are also teacher, administrator and leader (Bush, 2006).

Since this study focuses on leadership practices of institutional school, this study will be taking McEwan's (2003) model "7 steps to effective instructional leadership" as the theoretical lens. The first step in instructional leadership practices highlights the need for leaders to be aware of academic standards and establish them in the long run. To achieve this, the leader should thoroughly study a school's curriculum and sit with the teachers to prepare the instructional plan which is consistent with national curriculum standards; they should ensure that this plan is detailed and easy to understand and has continuous assessment plans that are 
explainable to staff and students in terms of their relevance and importance.

The second step in instructional leadership practices talks about leaders being an instructional source who constantly help to solve difficult instructional problems. To master this step, the leaders should be eager learners and discuss instruction and learning by utilizing the four Cs- collaboration, collegiality, cooperation, and creative problem solving. They need to read a variety of publications, attend all kinds of workshops, go to national conferences, present staff development programs to their teachers, and should be constantly on the lookout for potential resources for their buildings.

The third step focuses on leaders creating a school culture and climate conducive to learning. To achieve this goal, the leaders need to communicate with all the stake holders the expectations set for all of them to achieve maximum student learning outcome. The leaders also need to establish inclusive classrooms, good work-place environment, plan for extended learning opportunities for low achievers, etc., that help create conducive learning environments.

The fourth step suggest that instructional leaders should communicate the vision and mission of the school with its stakeholders and provide systematic two-way communication with staff regarding the achievement standards and the improvement goals of the school. They should establish, support, and implement activities like career awareness, academic clubs, student quality circle, etc. that communicate the value and meaning of learning to students.

According to step 5 instructional practices of leaders prioritize the setting of high expectations for the staff and leaders themselves. To achieve this, the leaders need to assist teachers in setting and reaching personal as well as professional goals. The leaders must also engage in planning of classroom observation and make regular classroom observation including both formal and informal. Lastly, the leaders need to conduct post observation conferences that provide 
thorough evaluations and make recommendations for personal and professional growth of the teacher.

The sixth step emphasizes on the need to develop teacher leaders. To achieve this, instructional leaders should schedule, plan, or facilitate regular meetings of all types (planning, problem solving, decision making, or in-service and training) with and among teachers to address instructional issues. They should be able to provide opportunities for, and training in, collaboration, shared decision making, coaching, mentoring, curriculum development, and presentations. Moreover, they should provide motivation and resources for faculty members to engage in professional growth activities.

The seventh step stresses on the notion that instructional leaders should communicate with students about their school life and serve as an advocate for them. To achieve this, the leaders should interact and familiarize themselves with students and should be engaged in at least 6 behaviours like calling students by their names, playing with them, celebrating students' success, attending student conferences, showing consideration for students' problems and participating in the resolution of such problems wherever appropriate.

\section{Research Methodology}

Since the study tries to explore the practice and perception of instructional leadership in institutional schools, this research has employed the narrative inquiry method as its research methodology offers practical and specific insights for this researcher looking for personal experiences (Creswell \& Poth, 2012). Clandinin \& Connelly, (2004) also viewed that experience happens narratively, and therefore, educational experience should be studied narratively. Principals' personal experience is of a central focus in this research. Therefore, two principals were chosen from different institutional schools. Principal- 1 is a male participant who has been in the educational field for the past 20 years. Similarly, principal- 2 is a female participant who has also been in the field for the last 15 years. They were purposely selected with a belief that their leadership experiences 
contribute to the inquiry of the research. As stated by Punch (2005), purposive sampling involves the existence of some purpose in mind.

Since the intent of research was to explore and articulate the practice of the principals on instructional leadership, this researcher was concerned about the quality of the relationships that would develop between the participants as this researcher was acquainted with them. Though initially this researcher had reservations about interviewing subjects whom he knew personally, he later found out that they were keen to share their experiences which were individual and unique. Thus, this researcher not only developed an insider's perspective, but also worked towards the sort of research relationship described by Connelly and Clandinin (2000) as where participants "feel cared for and have a voice with which to tell their stories".

This researcher interrogated both of them inside the school in their cabin during and even after the regular classes. The questions used were open ended and flexible so that this researcher could explore the perceptions of the respondents. While interviewing, this researcher kept very neutral and friendly to keep the participants in a comfort zone. In the beginning, this researcher started with introducing the research topic followed by further in-depth inquiry. Interviews were recorded and field notes were used as a method of recollecting information. Coding was made in the diaries for some of the information obtained from interviews and digital recordings were made of all the interviews. An elaborative process was adopted for coding, categorizing, and thematizing (Creswell, 2007). Then the experiences shared by the participants were analysed through a theoretical lens.

\section{Findings and Discussion}

Findings suggest that both the participants have different understanding on instructional leadership. This researcher found that both principal-1 and principal-2 followed step 4, 5 and 7 according to McEwan's 7 steps to instructional leadership which are elaborated in three different themes setting direction, focussing on curriculum and monitoring learners' progress. 


\section{Setting Direction}

When asked about instructional goals, principal- 1 stated the vision of the school as "creating an appropriate environment where all the stakeholders can excel in the skills to face the everyday world". He said that teachers integrate the element of child friendly activities based on the vision statement. He gave an example of teaching about the solar system in grade 2 . He said that a teacher would bring the students out from the classroom, draw the solar system on the ground and name each one them according to the name of the existing planets and let them revolve around the sun. This is related to Robinson's (2011) comment on instructional leaders to direct the work of teachers to develop clear and common goals. The Wallace Foundation (2013) also found that effective principals shape a vision of academic success for all students.

When it comes to the vision of the school, principal-2 said, "I haven't developed one yet. I think our vision is reflected in our bulky report card since our school is marks-oriented and we emphasize on exam achievements". She expressed her pride in being associated with a marks-oriented culture of teaching and learning. She strongly asserted that parents admit their children to her school because they want them to score good marks. Parents, she said, wanted a greater number of exams because they thought that such tasks kept the children occupied at home and improved exam marks at the same time. She considered achievement of marks as a traditional mode of thinking, though parents demanded such attitudes. Leithwood et al. (2004) identified setting directions as one of the three critical components of school leaders. Setting directions in this case includes incorporating daily lesson plan and activities with the vision statement of the schools.

In the school of principal-1, teachers are encouraged to include child friendly activities to enhance learning whereas in the case of principal2 , teachers are encouraged to achieve marks. Principal-2 claimed that it is because of such instructions that they have been able to achieve successful grades in SEE for more than a decade and awarded the best school by the Ministry of Education of Nepal. The organization for economic cooperation and development OECD research (2009) 
supports the view that successful instructional leaders are actively involved in ensuring that schools' goals are achieved.

\section{Focusing on Curriculum}

When questioned about the curriculum, principal-1 said that although they followed the national curriculum, they had a provision of sequential planning and the teachers stayed after school for lesson plan. So did their supervisors and department heads to support maintaining the quality. He said that they had sharing sessions and focused on team work. The supervisors would go to the classes with the teachers. They would see how it was operated and provided regular coaching and mentoring sessions. Based on the feedback the teachers would improve their sessions. These data suggests that principal 1 was more focused on modifying the curriculum according to the relevance and practicality of the contents being taught indicating flexible curriculum of the school. Sim (2011) had a similar view that the principals motivated and inspired the educators to plan and engage in classroom teaching in a way that was aligned with the school vision. Mulford \& Silins (2011) also said that successful principals involve others in the leadership process to increase and build capacity.

Principal-2 viewed that they too followed the national curriculum. However, the teachers did not prepare lesson objectives as they solely followed the books and they measured the success of students through examination marks. When asked why teachers were only limited to prescribed books? She said:

"We have teachers who have been working for 20 years and above. It is very difficult to change them as we have three types of teachers: teachers at the same level, growth level and elderly level. The same level means such types of teachers who has been working at the same level for many years. For example, the teachers of the primary section or pre-primary who do not want to initiate change. The elderly level teachers have very few years in their service and are very stubborn to accept change to improve teaching-learning; there are few growth level teachers who have helped sustain the quality of the school". 
Despite the professional development practices in her school, the data suggested obtained from principal-2 suggest that the teachers are reluctant to adopt new teaching and learning processes which also indicated that the text books were being followed without taking into consideration the relevance and practicality of the contents being taught. She referred the attitude of teachers using the famous quote, "a dog tail will not be straightening no matter how hard you try" suggesting that it is impossible for teachers to adopt any new change in the curriculum.

\section{Monitoring Learners' Progress}

Regarding the ways the school monitors the learners' progress and outcomes, assessments, principal-1 asserted that they follow formative assessment system whereby the students are assessed not just in terms of what they know but also in terms of their skills and understanding. To assess the learners' skills, teachers set criteria or indicators that help the teacher to know the level of the students and guide them accordingly. He shared an example to prove his point, -

Instead of explaining how seeds grow, the teachers ask students to bring seeds from home and ask them to monitor the growth. They inform them of the requirements for optimum plant growth but the students have the upper hand in taking care of the plant to ensure that it grows. The teachers observe the students and assess them not just in terms of whether the plant sprouted and grew into a bigger unit, but also in terms of other indicators set during the process like students' attitude and enthusiasm towards the experiment, their presentation on explaining their experiment, their new understanding and reflection.

The above suggests that the school focused on improving motor skills and $21^{\text {st }}$ century skills.

Principal-2, on the other hand, said:

There are a lot of examinations and the teachers are always correcting copies and filling in their report cards. There is no time for teachers to go for training to develop their professional skills. 
Moreover, when asked as to why she had kept such a busy schedule for the teachers, she replied that the school was known for achieving good scores in SEE examination and parents admitted their children because they appreciated the values created by the school. That was the reason for having six (06) exams annually which satisfied the parents. The above data suggests that principal-2's school followed summative assessment system. Whether it is formative or summative the data indicated that both the schools have organized practice of assessment to help parents understand about how their children are performing.

Thus, the above findings revealed that both the principals did not seem to have in-depth knowledge of instructional leadership as the study revealed that they were unaware of McEwan's step 1, 2, 3, and 6 of instructional leadership practices. However, they attempted to achieve effective learning and teaching by setting direction, setting expectations in the way the curriculum was taught and monitoring learners' progress thus suggesting that they follow McEwan's step 4, 5 and 7.

The theme "setting direction" is aligned with step-4 of McEwan's 7 steps to effective instructional leadership. In step-4, according to McEwan (2003), instructional leaders should able to communicate the vision and mission of the school to their teachers. He or she must have a clear vision of what the school should be and should become at some time in the future. In the case of principal-1, he has a welldefined vision and seems to encourage teachers to align lesson plans based on the vision of the school. It is aligned with what Harris et al. (2008) claimed that goal setting is considered as one of the key dimensions of success for a successful school leader. This shows that he is following step-4 of McEwan. In case of principal-2 although she claimed she was unaware of the vision of the school; the goal of the school was to ensure students excellence in SEE results and to satisfy those parents who admitted their children to obtain good grades in the examination. This suggests that although she was unknown about the vision, McEwan step 4 theme setting direction was indirectly observed by this researcher since the school strove to achieve excellent SEE results. 
Similarly, the theme "focusing on curriculum" align with step-5 emphasizes that the instructional leader should able to set high expectations for the staff and oneself. According to McEwan (2003) a principal should engage in planning classroom observations, post observation conferences that focus on the improvement of instructions. In the case of principal-1, he supported and mentored teachers in designing daily lesson plans and providing constructive feedback to make sure that each lesson plan incorporated the activities that helped achieve the vision of the school. This shows principal-1 exercised collaborative and collegial environment to enhance the effective teaching of the curriculum. On the other hand, principal-2 expressed her negative experiences with the existing teachers. The teachers' negative attitude towards her efforts to check students' answer scripts and conflicting meetings among teachers showed that there was resistance to her mode of operation of the school. Since there was no visionary thinking in the school of principal-2, their whole effort was to secure good scores in the examinations.

The theme "monitoring the learners' progress" aligns with step-7 that strongly advocates that the instructional leader should show their concern for students and prioritize their development. Effective instructional leaders do not engage in mindless chatter about how much they care about students. They demonstrate such thoughts through their actions. On a daily basis, they work to change practices in the areas of discipline and their achievements. With this reference, in the case of principal-1, he practiced formative assessment. Teachers were given full responsibility and the progress of the students were being measured in terms of acquiring knowledge and skills. Whereas in the case of principal-2, she was found to be practicing summative assessment and students' progress were measured in terms of obtaining scores in the examinations.

\section{Conclusions}

From the above data and discussion, it is concluded that both the principals perceived and practiced instructional leadership as setting 
direction, focusing on curriculum and monitoring learners' progress. On one hand, principal-1 had a vision to engage students, so he seemed to be focusing on every activity and progress of the students to achieve the set goals. On the other hand, principal-2, was marksoriented and thus, focused mainly in achieving good scores in the examination. Moreover, principal-1's school gave priority to developing teacher leaders, building strong relationship among stakeholders and to create a culture conducive to learning whereas principal-2's school seemed to be uninformed on the knowledge and skills in developing a teacher leader, teacher as an instructional source, a school culture and most importantly, positive relations with students and parents.

This study had several limitations including the limited time and resources. As only two principals were selected as participants, the conclusion of this study can hardly be generalized. Another limitation is that this study was carried out only on two secondary school principals of the Kathmandu district. Similar studies need to be carried out covering a wide area and a larger number of such schools so that the results could be generalized. Another limitation is that this study was carried out only to explore the perception and practice of instructional leadership of principals but not of other teachers, nonteaching staff, students, parents and school management committee members. If their perceptions were added the findings could vary. Finally, multimethod to collect the data from informants to triangulate the data for reliability and validity of the data would have been the better methods for this study. In this connection, use of other methods such as observation, focus group discussion, collection of artifacts, etc. would be further relevant. Multiple interviews as well as multi-method data collection procedures would have been ideal for the saturation of the research themes. However, the researcher realized that the data provided by both the principals and their analysis provided a strong foundation for more in-depth examination of the existing practices of instructional leadership. 


\section{References}

Bush, T. (2006). 'The National College for School Leadership: a successful English innovation?' Phi Delta Kappan, 87(7): 50811.

Bush, T. (2007). Educational leadership and management: Theory, policy and practice. South African Journal of Education,27(3), 391-406.

Connelly, F. M. \& Clandinin, D. J. (2000). Narrative understandings of teacher knowledge. Journal of Curriculum and Supervision, 15(4), 315-331.

Clandinin, D. \& Connelly, F. (2004). Narrative inquiry: experience and story in qualitative research. John Wiley \& Sons, Inc.

Creswell, J. W. (2007). Qualitative inquiry \& research design: Choosing among five approaches (2 ${ }^{\text {nd }}$ ed.). Thousand Oaks, CA: Sage.

Creswell, J. W. \& Poth, C. N. (2012). Qualitative inquiry \& research design: Choosing among five approaches (3rd ed.). Thousand Oaks, CA: Sage.

Hallinger, P. \& Heck, R. H. (1998). Exploring the Principal's Contribution to School Effectiveness: 1980- 1995. School effectiveness and school improvement, 9(2). 157-191. DOI:10.1080/0924345980090203

Harris, A. (2009). Distributed knowledge and knowledge creation. In K. Leithwood, B. Mascall \& T. Strauss (Eds.), Distributed leadership according to the evidence (pp. 253-266). New York, NY: Routledge.

Hallinger, P. (2003). Leading educational change: Reflections on the practice of instructional and transformational leadership. Cambridge Journal of Education, 33(3), 329351. https://doi.org/10.1080/0305764032000122005.

Huber, S. (2004). 'Context of research', in S. Huber (ed.), Preparing School Leaders for the 21st Century: An International Comparison of Development Programs in 15 Countries. London: Routledge Falmer. 
Leithwood, K. A., Louis, K. S., Anderson, S. \& Wahlstrom, K. (2004). How leadership influences student learning: review of research. The Wallace foundation.

Leithwood, K., Day, C., Sammons, P., Harris, A. \& Hopkins, D. (2006). Seven Strong Claims about Successful School Leadership. London: Department for Education and Skills.

Leithwood, K., Harris, A., \& Hopkins, D. (2008). Seven strong claims about successful school leadership. School leadership and management, 28(1), 27-42. DOI:10.1080/13632430701800060.

Louis, K. S. \& Wahlstrom, K (2012). Shared and instructional leadership. In K. Leithwood \& K. S. Louis (Eds) Linking leadership to student learning. San Franscisco, CA: Josey-Bass.

Louis, K. S., Leithwood, K., Wahlstrom, K., Anderson, S., Mascall, B., Michlin, M. \& Thomas, E. (2010). Learning from districts' efforts to improve student's achievement. Report to Wallace foundation (draft).

McEwan, E. K. (2003). Seven steps to effective instructional leadership. Thousand Oaks, CA: Corwin Press, Inc. http://dx.doi.org/10.4135/9781483328775.n2.

Mulford, B. \& Silins, H. (2011). Revised models and conceptualisation of successful school principalship for improved student outcomes. International Journal of Educational Management, 25(1), 61-82.DOI:10.1108/09513541111100125.

OECD, (2009). Creating Effective Teaching and Learning Environments. First Results from TALIS. Paris: OECD Publications.

Punch, K. (2005). Introduction to social research: Quantitative and qualitative approaches. Sage Publications, Inc. DOI: https://doi.org/10.17169/fqs-7.2.109.

Robinson, V. M. J. (2011). Student-Centered Leadership. San Francisco: Jossey-Bass.

Salo, P., Nylund, J. \& Stjernstrom, E. (2014). On the practice architectures of instructional leadership. Educational Management Administration and Leadership, 43(4), 490-506. DOI: $10.1177 / 1741143214523010$. 
Sebastian, J., \& Allensworth, E. (2012). The influence of principal leadership on classroom instruction and student learning: A research of mediated pathways to learning. Educational Administration and Leadership, 39(2), 219-227. https://doi.org/10.1177/0013161X11436273.

Sim, Q. C. (2011). Instructional leadership among principals of secondary schools in Malaysia. Educational Research, 2(12), 2141-5161.

Spiro, J. D. (2013). Effective principals in action. Phi Delta Kappan, 94(8), 27-31. https://doi.org/10.1177/003172171309400807.

The Wallace Foundation. (2013). The school principal as leader: Guiding schools to better teaching and learning. New York, NY: Author. 